\title{
Inhibitory effect of emodin on migration, invasion and metastasis of human breast cancer MDA-MB-231 cells in vitro and in vivo
}

\author{
YANG SUN $^{1 *}$, XIUFENG WANG ${ }^{1,2^{*}}$, QIANMEI ZHOU ${ }^{1}$, YIYU LU $^{1}$, HUI ZHANG $^{1}$, \\ QILONG CHEN $^{1}$, MING ZHAO ${ }^{1,3}$ and SHIBING SU ${ }^{1 *}$ \\ ${ }^{1}$ Research Center for Traditional Chinese Medicine Complexity System, Shanghai University of \\ Traditional Chinese Medicine, Shanghai 201203; ${ }^{2}$ Fujian Academy of Traditional Chinese Medicine, \\ Fuzhou, Fujian 350003, P.R. China; ${ }^{3}$ AntiCancer Inc., San Diego, CA 92111, USA
}

Received June 29, 2014; Accepted October 6, 2014

DOI: $10.3892 /$ or.2014.3585

\begin{abstract}
In breast cancer, metastasis is the main reason for patient mortality. In the present study, we used breast cancer MDA-MB-231 cells and a mouse xenograft model to demonstrate the effect of emodin on the migration, invasion and metastasis of human breast cancer MDA-MB-231 cells and the related mechanisms. In vitro, wound healing and Transwell assays showed that emodin dose-dependently inhibited the migration and invasion of MDA-MB-231 cells. Enzyme-linked immunosorbent assay (ELISA) showed that emodin decreased the secretion of MMP-2 and MMP-9. Western blot analysis showed that emodin downregulated the expression levels of MMP-2, MMP-9, uPA and UPAR as well as p38 inhibitor SB203580 and ERK inhibitor PD980559, even though TIMP-1 and TIMP-2 were not obviously changed in the MDA-MB-231 cells. Furthermore, emodin inhibited the activity of p38 and ERK1/2 in the MDA-MB-231 cells. In vivo, emodin inhibited lung metastasis in mice bearing the breast cancer MDA-MB-231 xenografts with no obvious changes in body weight, liver and kidney functions. These results indicated that emodin inhibited the lung metastasis of human breast cancer in a mouse xenograft model, and inhibited the invasion of MDA-MB-231 cells associated with the downregulation of MMP-2, MMP-9, uPA and uPAR expression as well as decreased activity of p38 and ERK.
\end{abstract}

\section{Introduction}

Breast cancer is the most common malignant tumor in women worldwide and most patients with advanced breast cancer

Correspondence to: Professor Shibing Su, Research Center for Traditional Chinese Medicine Complexity System, Shanghai University of Traditional Chinese Medicine, Shanghai 201203, P.R. China E-mail: shibingsu07@163.com

*Contributed equally

Key words: emodin, breast cancer, MDA-MB-231 cells, metastasis, migration, invasion have serious systemic metastasis, which is associated with a high death rate (1). Chemotherapy is commonly used in the treatment of metastatic breast cancer. However, this treatment remains ineffective due to its toxicity to normal cells (2). Natural medicine has been widely used for treating malignant tumors for thousands of years $(3,4)$. There is great potential in identifying drugs from natural medicine for the treatment of metastatic breast cancer due to their wide range of biological activities and low toxicity.

Emodin (6-methyl-1,3,8-trihydroxyanthraquinone) (Fig. 1A), an active monomer extracted fromRheum, Polygonum,Buckthorn and Senna, has been shown to be active against pancreatic $(5,6)$, lung $(7,8)$, breast $(9,10)$, liver $(11)$, prostate $(12,13)$, ovarian $(14)$, cervical (15), colon (16), gallbladder (17) and human tongue cancer SCC-4 cells $(18,19)$. Moreover, it has been reported that emodin induces apoptosis of human breast cancer MCF-7 (20) and MDA-MB-453 cells (21). However, there are no reports on the effect of emodin on breast cancer MDA-MB-231 cells.

Proteolytic enzymes play important roles in the process of cancer development and metastasis. Its members such as MMP-2, MMP-9 and uPA play important roles in breast cancer metastasis, by degrading the extracellular matrix (ECM) and basement membrane (BM) to facilitate invasion and migration of cancer cells (22-24).

Previous studies have shown that the mitogen-activated protein kinase (MAPK) signaling pathway is associated with the invasion and migration of breast cancer cells through degradation of ECM $(25,26)$. In the present study, we demonstrated the efficacy of emodin treatment on breast cancer cell migration, invasion and metastasis, and confirmed that emodin inhibits the invasion, migration and metastasis of MDA-MB231 cells in vivo and in vitro. Emodin may function as an inhibitor of p38 and ERK in the regulation of MAPK signaling pathways through downregulation of MMP-2, MMP-9, uPA and UPAR expression.

\section{Materials and methods}

Materials. Emodin was obtained from the Shanghai Standardization for the Traditional Research Center and was dissolved in dimethyl sulfoxide (DMSO). Matrigel was purchased from Sigma (St. Louis, MO, USA) and 
3-(4,5-dimethylthiazol-2-yl)-5-(3-carboxymethoxyphenyl)2-(4-sulfophenyl)-2H-tetrazolium, inner salt (MTS) was purchased from Promega (Madison, WI, USA). SB203580 and PD98059 were obtained from Biomol (Plymouth, PA, USA). The antibodies used in the present study were MMP-9, MMP-2, TIMP-1, TIMP-2, uPA and UPAR and were from Santa Cruz Biotechnology (Santa Cruz, CA, USA); p38, p-p38, ERK2 and p-ERK1/2 were from Cell Signaling Technology (Boston, MA, USA). IRDye ${ }^{\mathrm{TM}}$ fluorescence antibodies were obtained from LI-COR Biosciences (Lincoln, NE, USA).

Cell culture. Human breast cancer MDA-MB-231 cells were obtained from the American Type Culture Collection (ATCC, Manassas, VA, USA) and cultured in RPMI-1640 medium supplemented with $10 \%$ fetal calf serum, $0.01 \mathrm{mg} / \mathrm{ml}$ insulin, $2 \mathrm{mM}$ glutamine, $100 \mathrm{U} / \mathrm{ml}$ penicillin and $100 \mu \mathrm{g} / \mathrm{ml}$ streptomycin at $37^{\circ} \mathrm{C}$ with $5 \% \mathrm{CO}_{2}$ in a humidified atmosphere.

Cell viability assay. Cell viability was determined by MTS assay. Briefly, MDA-MB-231 cells $\left(5 \times 10^{4}\right.$ cells/well) were seeded in 96-well culture plates. After overnight incubation, various concentrations of emodin were added to the cells for varying times followed by the addition of $20 \mu \mathrm{MTS}$ at $37^{\circ} \mathrm{C}$ for $4 \mathrm{~h}$. Optical density (OD) was measured at $490 \mathrm{~nm}$ using an ELISA plate reader (BioTek, Winooski, VT, USA).

Wound healing assay. MDA-MB-231 cells were seeded at a density of $1-5 \times 10^{5}$ cells/well in 12 -well culture plates and allowed to form a confluent monolayer. The layer of cells was scraped with a 20-200 $\mu 1$ micropipette tip to create a wound of $\sim 1 \mathrm{~mm}$ width. Cells were washed twice with PBS and replaced with serum-free medium containing various concentrations of emodin. At 0, 24, 48 and $72 \mathrm{~h}$, cells were washed with PBS and then fixed with $4 \%$ paraformaldehyde followed by staining with $0.5 \%$ Coomassie brilliant blue. Images of the wounds were monitored under a phase-contrast microscope at x100 magnification.

Migration and invasion assays. Cell migration was analyzed with the aid of a Transwell (Corning Incorporated, Corning, NY, USA). To analyze cell invasion, the upper surface of a filter membrane in the upper compartment of a Transwell was coated with $30 \mu \mathrm{g}$ Matrigel. Cells $\left(1 \times 10^{5}\right)$ suspended in $200 \mu \mathrm{l}$ of serum-free medium were seeded onto the upper compartment of the Transwell and the lower chambers were filled with medium containing $10 \%$ FCS and various concentrations of emodin. After $24 \mathrm{~h}$, the cells remaining in the upper chamber were removed and cells on the undersurface of the filters were fixed with $70 \%$ ethanol followed by staining with $0.5 \%$ Coomassie brilliant blue for $10 \mathrm{~min}$. The migrated or invaded cells were visualized and counted from six randomly selected fields (magnification, x100) under a phase-contrast microscope.

Effects of emodin on breast cancer MDA-MB-231 xenografts. Six-week-old female athymic nude mice were obtained from the Laboratory Animal Center at the Shanghai University of Traditional Chinese Medicine and were housed in a pathogenfree condition throughout the experimental duration. All procedures conformed to the consideration of animal welfare and were approved by the Ethical Committee of Shanghai Traditional Chinese Medicine. Briefly, mice were injected with $3 \times 10^{6}$ MDA-MB-231 cells (suspended in Matrigel). One day after tumor cell inoculation, the mice received either $1 \%$ DMSO/10\% Tween-80 in PBS (sham-treated group, $n=8$ ) or $40 \mathrm{mg} / \mathrm{kg}$ emodin (emodin-treated group, $\mathrm{n}=8$ ) every two days through intraperitoneal injection. Mice were closely monitored, their bodies were weighed and tumor weights were measured weekly. Eight weeks after tumor cell inoculation, the mice were sacrificed and tumors were excised. Lungs were also collected from the sacrificed animals, sectioned and stained with hematoxylin and eosin $(\mathrm{H} \& \mathrm{E})$. Representative fields for each group were photographed, and the metastatic nodules were counted.

Function tests of the liver and kidney. At the time of necropsy, $1 \mathrm{ml}$ of blood was collected through eye-bleeding and centrifuged at 3,000 rpm for $10 \mathrm{~min}$ to obtain sera. Sera were analyzed for the levels of glutamic oxalacetic transaminase (GOT), glutamic pyruvic transaminase (GPT), creatinine $(\mathrm{Cr})$ and urea nitrogen (BUN) using the respective colorimeter testing kits (Jiancheng Bioengineering Institute, Nanjing, China) according to the manufacturer's instructions.

Enzyme-linked immunosorbent assay (ELISA). To detect the effect of emodin on the secretion of MMP-2 and MMP-9 from MDA-MB-231 cells, the cells were treated with 20, 40 and $80 \mu \mathrm{M}$ emodin for $24 \mathrm{~h}$. Supernatants were then collected and analyzed by ELISA using human MMP-9 (R\&D Systems, Minneapolis, MN, USA) and human MMP-2 ELISA kits (Ray Biotech, Norcross, GA, USA) according to the manufacturer's instructions.

Western blot analysis. Whole cell lysates were electrophoresed on 8 or $10 \%$ SDS-PAGE. The levels of MMP-2, MMP-9, TIMP-1, TIMP-2, uPA, uPAR, p38, p-p38, ERK2, p-ERK1/2 and GAPDH were detected by first incubating with the respective primary antibodies $(1: 1,000-5,000)$ and visualized by IRDye $^{\text {TM }} 700 D X$ (red) or IRDye ${ }^{\text {TM }} 800 D X$ (green) conjugated secondary antibodies (1:10,000-20,000). Images were generated using the Odyssey Infrared Imaging system (LI-COR Biosciences). Quantitative analyses of western blots were performed using the AlphaEase FC (FluorChem FC2) software. Relative protein expression was standardized to the level of GAPDH.

Statistical analyses. All data are the means \pm SD. Comparisons between groups were analyzed by the Student's t-test and one-way analysis of variance (ANOVA). $\mathrm{P}<0.05$ was considered to indicate a statistically significant result.

\section{Results}

Emodin inhibits breast cancer cell migration. To determine the general effect of emodin on breast cancer cell survival, varying concentrations of emodin were added to the MDA-MB-231 cell culture for up to 3 days. MTS assay showed that cell survival was significantly decreased after cells were treated with emodin at concentrations of 20,40 and $80 \mu \mathrm{M}$ for 48 and $72 \mathrm{~h}$ (vs. the untreated cells, $\mathrm{P}<0.05$ ) (Fig. 1B). Subsequently, the effect of emodin on cell migra- 
$\mathbf{A}$<smiles>Cc1cc(O)c2c(c1)C(=O)c1cc(O)cc(O)c1C2=O</smiles>

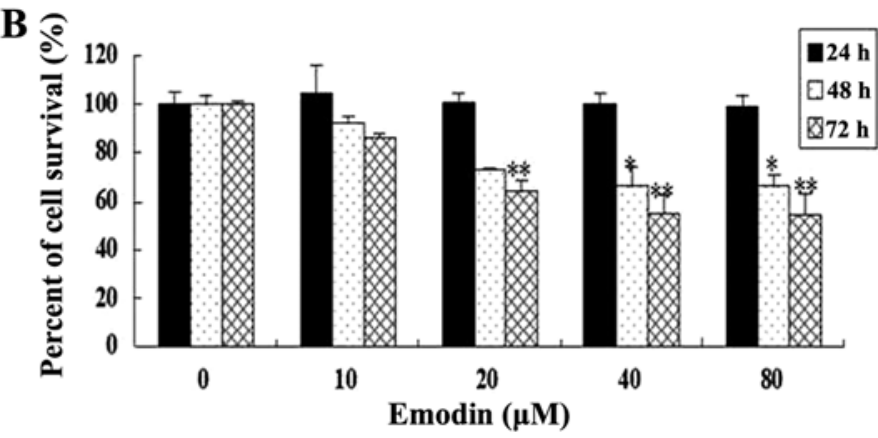

Figure 1. Chemical structure and effect of emodin on MDA-MB-231 cell viability. (A) Chemical structure of emodin. (B) Effect of emodin on breast cancer cell viability. The effects of emodin on MDA-MB-231 cell viability were observed by MTS assay. Cells were treated with emodin at $10,20,40$ and $80 \mu \mathrm{M}$ for 24,48 and $72 \mathrm{~h}$, respectively. Results are presented as means $\pm \mathrm{SD}$ of three independent experiments; $\mathrm{SD}$ is denoted by the error bars. ${ }^{*} \mathrm{P}<0.05,{ }^{* * *} \mathrm{P}<0.01, \mathrm{vs}$. untreated cells.

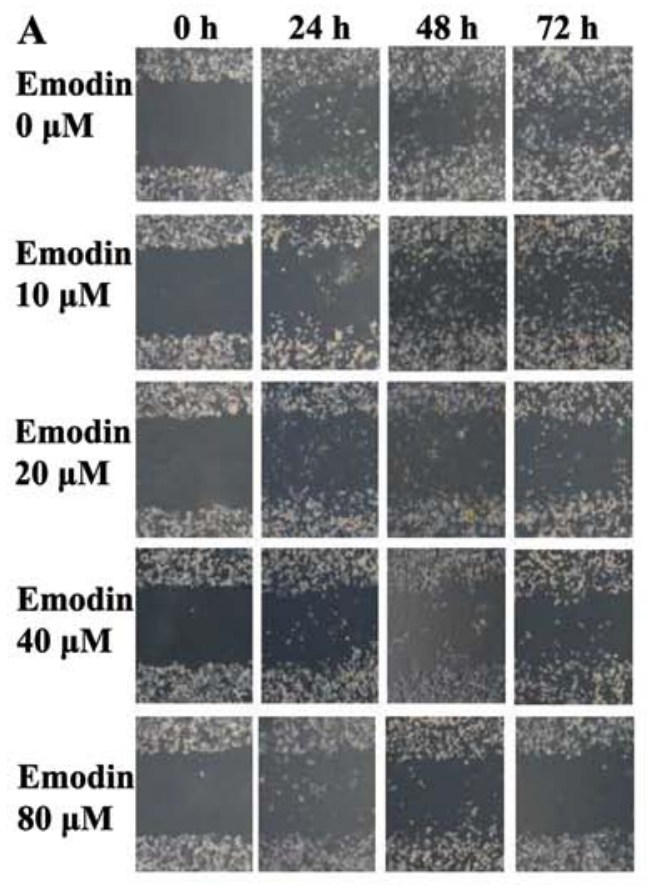

\section{B}
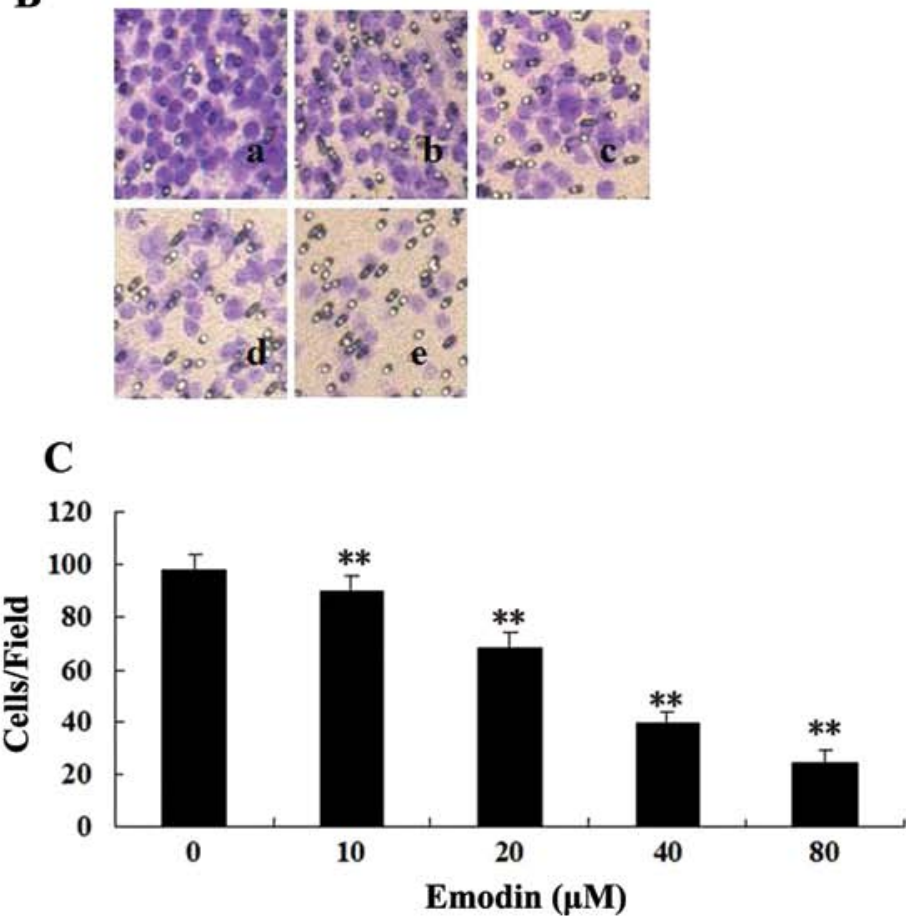

Figure 2. Effect of emodin on MDA-MB-231 cell migration. (A) Images of wound healing assays (magnification, x100). Cells were seeded into 12-well cell culture plates and cultured to near confluency. The wounded monolayer was incubated in free-FCS RPMI-1640 containing $0,10,20,40$ and $80 \mu \mathrm{M}$ of emodin for 24, 48 and $72 \mathrm{~h}$. (B) A Transwell chamber was used for the migration assay (magnification, x200). MDA-MB-231 cells were treated with (a) 0, (b) 10, (c) 20, (d) 40 or (e) $80 \mu \mathrm{M}$ of emodin for $24 \mathrm{~h}$. (a) Blank (no added cells). (C) Percent of cell migration. Results are presented as means \pm SD of three independent experiments; $\mathrm{SD}$ is denoted by the error bars. ${ }^{* *} \mathrm{P}<0.01$, vs. untreated cells.

tion was examined by performing a wound healing assay with non-lethal concentrations and incubation periods $(\leq 80 \mu \mathrm{M}$, $\leq 72 \mathrm{~h})$. As shown in Fig. 2A, the wound gaps in the 10, 20,40 and $80 \mu \mathrm{M}$ emodin-treated groups were significantly wider than those of the untreated groups at 24,48 and $72 \mathrm{~h}$. The cell migration was further analyzed by Transwell assay. Similar to the results of the wound healing assay, emodin effectively inhibited cell migration in a dose-dependent manner, and an $\sim 7,30,60$ and $75 \%$ reduction could be observed in the MDA-MB-231 cells treated with 10, 20, 40 and $80 \mu \mathrm{M}$ emodin, respectively (Fig. 2B and C). The results indicated that emodin can effectively inhibit the motility of MDA-MB231 cells, since emodin shows a small effect on cell viability at these concentrations.
Emodin inhibits breast cancer cell invasion. To determine the effect of emodin on cell invasion, MDA-MB-231 cells were treated with 10,20,40 and $80 \mu \mathrm{M}$ emodin followed by allowing cells to invade in Matrigel-coated Transwells for $24 \mathrm{~h}$. The number of cells that invaded was reduced by emodin in a dosedependent manner (Fig. 3). Compared to the untreated group, emodin at 40 and $80 \mu \mathrm{M}$ suppressed invasion by $\sim 57$ and $44 \%$, respectively. These data clearly showed that emodin is a strong suppressor of breast cancer cell invasion.

Emodin reduces $M M P-2$ and $M M P-9$ secretion from MDA-MB-231 cells. MMP-2 and MMP-9 are known to play an essential role in cancer cell invasion and metastasis by facilitating the degradation of ECM and BM. Amounts 
A

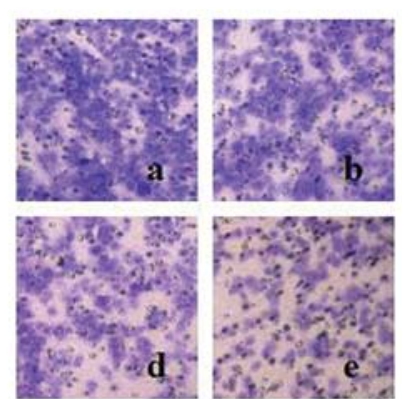

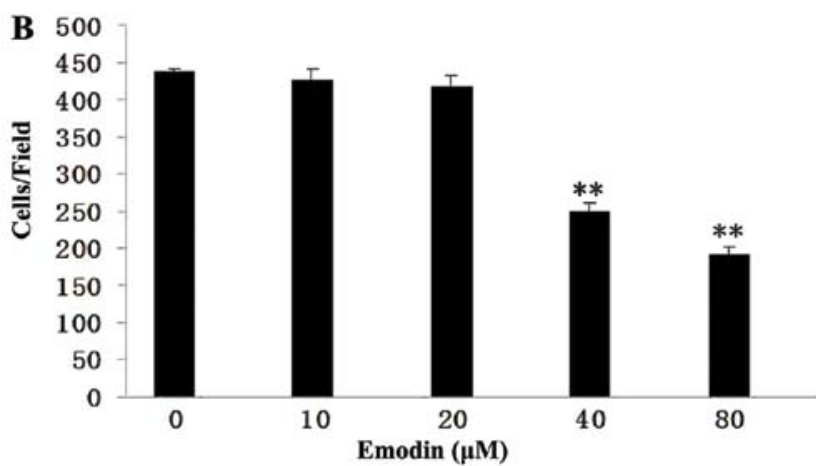

Figure 3. Effect of emodin on MDA-MB-231 cell invasion. (A) A Transwell chamber was used for the invasion assay and images were captured (magnification, x200). The filter membranes were coated with Matrigel. MDA-MB-231 cells were treated with (a) 0, (b) 10, (c) 20, (d) 40 or (e) $80 \mu \mathrm{M}$ of emodin for $24 \mathrm{~h}$. No cells were seeded in (a). (B) Results are presented as means \pm SD of three independent experiments; SD is denoted by the error bars. ${ }^{* *} \mathrm{P}<0.01$, vs. untreated control.

A

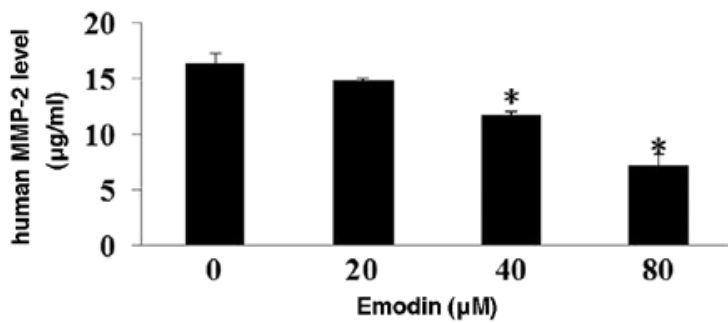

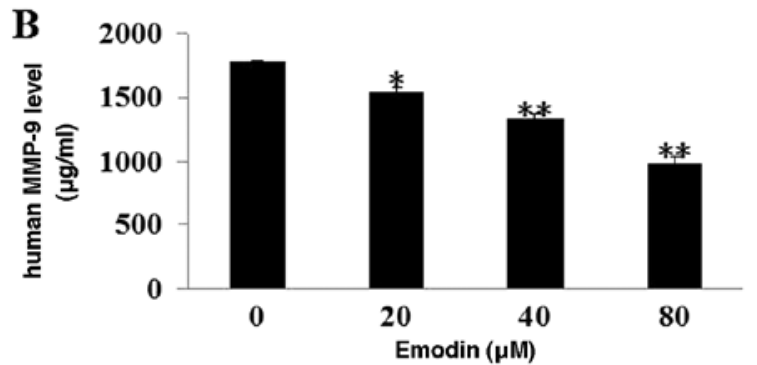

Figure 4. Emodin reduces the extracellular secretion of MMP-2 and MMP-9 in MDA-MB-231 cells. MDA-MB-231 cells were treated for $24 \mathrm{~h}$ with the indicated concentrations of emodin. Then each cell culture medium was collected and analyzed by ELISA using (A) human MMP-2 and (B) MMP-9 ELISA kits. ELISA was conducted according to the manufacturer's instructions. Each experiment was repeated 3 times. ${ }^{*} \mathrm{P}<0.05$ and ${ }^{* *} \mathrm{P}<0.01$, vs. untreated control.
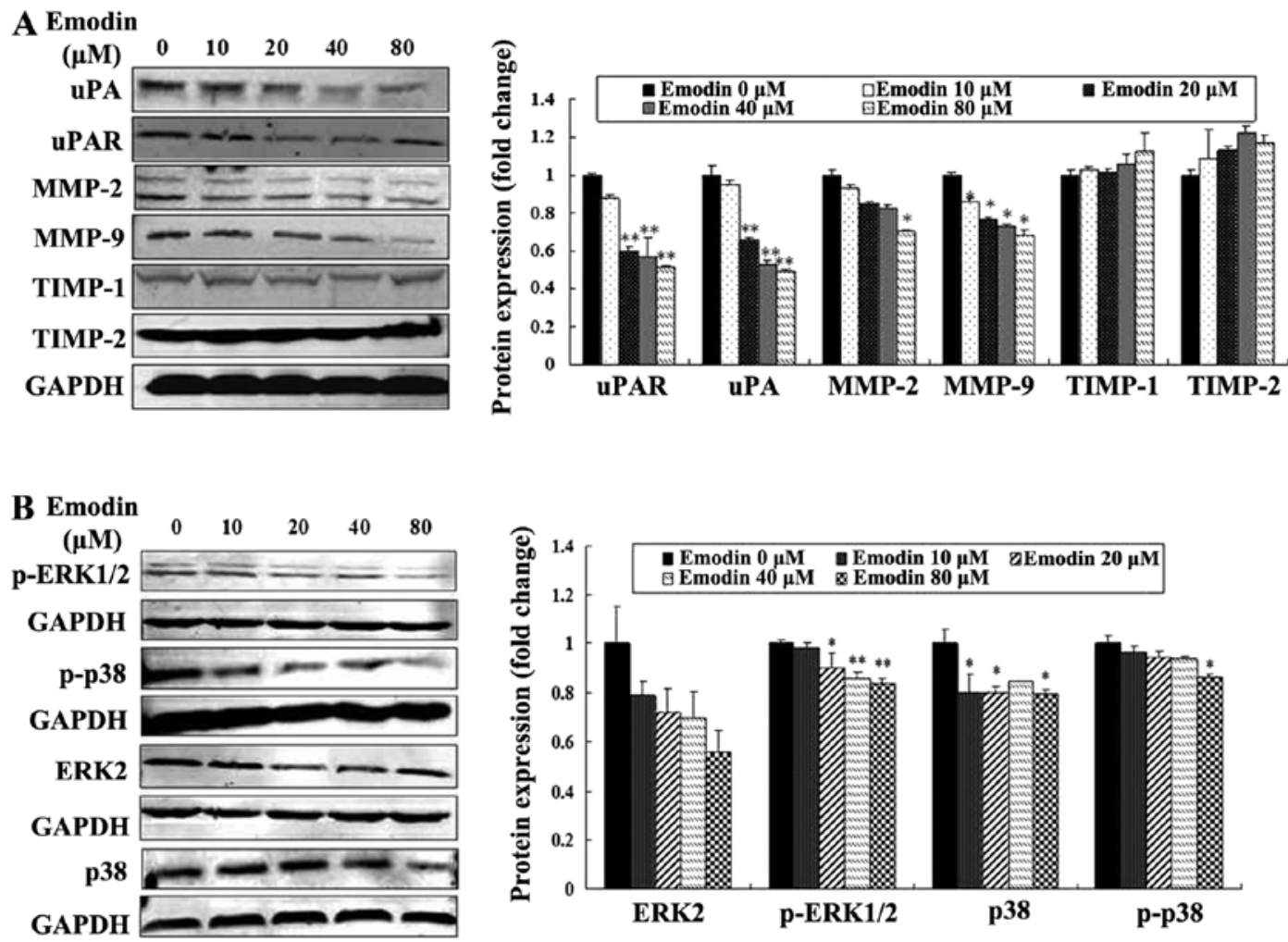

Figure 5. Effects of emodin on proteolytic enzymes and MAPK in MDA-MB-231 cells. Cells were treated with or without 10, 20, 40 and $80 \mu \mathrm{M}$ emodin for $24 \mathrm{~h}$. The proteins were analyzed by western blotting. The density ratio of proteins to emodin PDH is shown as relative expression. (A) uPA, uPAR, MMP-2 and MMP-9, TIMP-1 and TIMP-2 expression. (B) p38, p-p38, ERK1/2 and p-ERK expression. Values are expressed as means \pm SD. Experiments were repeated 3 times. ${ }^{*} \mathrm{P}<0.05$ and ${ }^{* *} \mathrm{P}<0.01$, vs. untreated cells. 
A

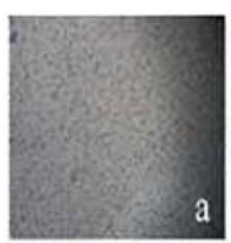

a
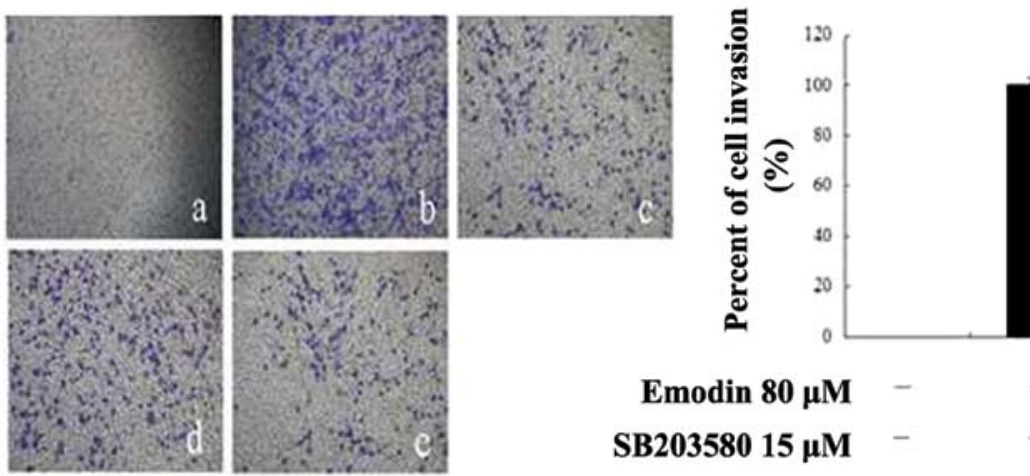

Emodin $80 \mu \mathrm{M}$
$\mathrm{SB203580} 15 \mu \mathrm{M}$
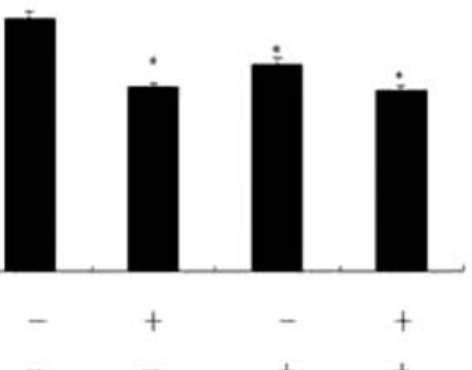
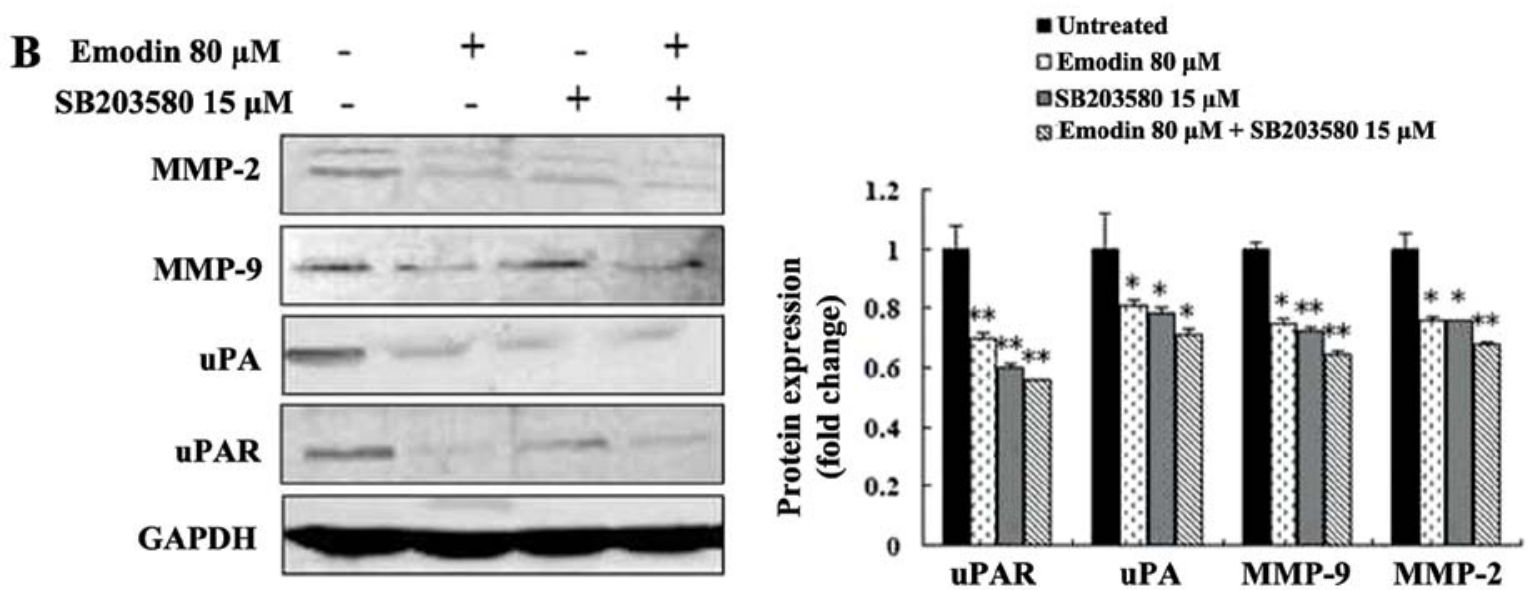

Figure 6. Effect of emodin, SB203580 and their combination on MDA-MB-231 cell invasion and MMP-2, MMP-9, uPA and uPAR expression. (A) A Transwell chamber was used for the invasion assay (magnification, $\mathrm{x} 100$ ). The filter membranes were coated with Matrigel. Cells were untreated (b) or treated with $80 \mu \mathrm{M}$ emodin (c), $15 \mu \mathrm{M}$ SB203580 (d) or $80 \mu \mathrm{M}$ emodin plus $15 \mu \mathrm{M}$ SB203580 (e) for $24 \mathrm{~h}$. (a) Blank (cells were not added). Results are presented as means \pm SD of three independent experiments. ${ }^{* *} \mathrm{P}<0.01$ vs. untreated cells. (B) MDA-MB-231 cells were treated with or without $80 \mu \mathrm{M}$ emodin, or $15 \mu \mathrm{M}$ SB203580 or $80 \mu \mathrm{M}$ emodin plus $15 \mu \mathrm{M}$ SB203580 for $48 \mathrm{~h}$. The proteins were analyzed by western blotting. The density ratio of proteins to GAPDH was shown as relative expression. Values are expressed as means $\pm \mathrm{SD}$. Experiments were repeated three times. ${ }^{*} \mathrm{P}<0.05$ and ${ }^{* *} \mathrm{P}<0.01$ vs. untreated cells

of MMP-2 and MMP-9 secreted from MDA-MB-231 cells were measured with or without emodin treatment. As shown in Fig. 4A and B, emodin greatly decreased the secretion of MMP-2 and MMP-9 from MDA-MB-231 cells $(\mathrm{P}<0.01)$.

Emodin inhibits the expression of $M M P-2, M M P-9, u P A$, $u P A R, p 38$ and ERK. To determine whether the expression of proteolytic enzymes, p38 and ERK were affected by emodin, the levels of MMP-2, MMP-9, uPA, uPAR, TIMP-1 and TIMP-2, p38, p-p38, p-ERK1/2 and ERK2 were evaluated in MDA-MB-231 cells treated with or without emodin. Western blotting with the respective antibodies showed that the expression levels of UPA, uPAR, MMP-2 and MMP-9 were concentration-dependently decreased by emodin treatment $(\mathrm{P}<0.05$ or $\mathrm{P}<0.01$; Fig. $5 \mathrm{~A})$. The levels of TIMP-1 and TIMP-2 were increased, but they were not significantly altered by emodin treatment $(\mathrm{P}>0.05$; Fig. 5A). Moreover, emodin also reduced the expression levels of p38, p-p38 and p-ERK1/2 without altering the levels of ERK2 expression $(\mathrm{P}<0.05$ or $\mathrm{P}<0.01$; Fig. 5B). These results indicate that emodin is most likely to inhibit MDA-MB-231 cell migration, invasion and metastasis by downregulating the levels of UPA, UPAR, MMP-2 and MMP-9 proteolytic enzymes, and reducing activities of p38 and ERK.
Emodin, SB203580 and PD98059 inhibit cell invasion by regulating the expression of $M M P-2, M M P-9, u P A$ and $u P A R$. To investigate the potential functional link between the expression of proteolytic enzymes, ERK and p38, we treated MDA-MB-231 cells with the p38-specific inhibitor SB203580 and ERK-specific inhibitor PD98059 in the presence or absence of emodin followed by analysis of cell invasion and proteolytic protein expression. Both the invasive ability of MDA-MB-231 cells and the expression levels of MMP-2, MMP-9, uPA and UPAR were significantly suppressed by $15 \mu \mathrm{M}$ SB203580 (Fig. 6), $25 \mu \mathrm{M}$ PD98059 (Fig. 7) and 80 $-\mu \mathrm{M}$ emodin treatment $(\mathrm{P}<0.05$ or $\mathrm{P}<0.01$; Figs. 6 and 7$)$, respectively. However, the treatment of SB203580 or PD98059 and combination with emodin did not exhibit a significantly greater inhibitory effect ( $\mathrm{P}>0.05$; Figs. 6 and 7). These results indicate that emodin is most likely to decrease MMP-2, MMP-9, uPA and UPAR expression and in vitro invasion as well as p38- and ERK-specific inhibitors.

Effects of emodin on breast cancer MDA-MB-231 cell xenografts. The ability of emodin to potently block in vitro invasion prompted us to investigate its effectiveness to inhibit in vivo metastasis. After athymic nude mice were injected with MDA-MB-231 cells for one day followed by (every two days) 
A
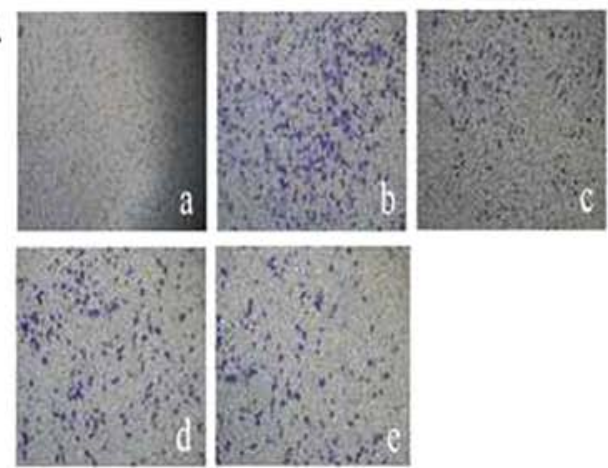

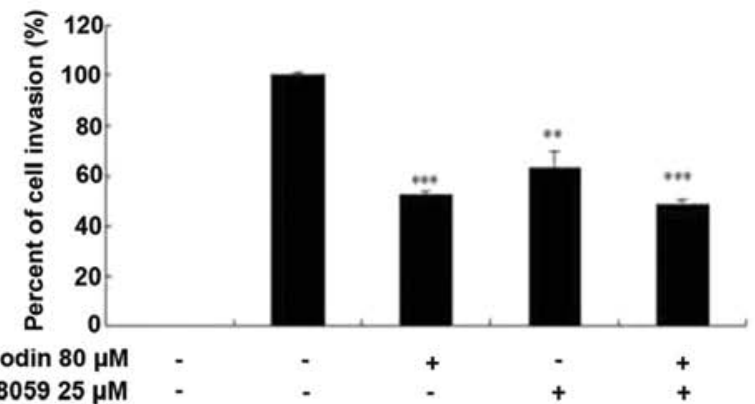

Untreated

口Emodin $80 \mu \mathrm{M}$

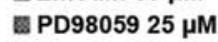

B Emodin $80 \mu \mathrm{M}$
PD98059 $15 \mu \mathrm{M}$

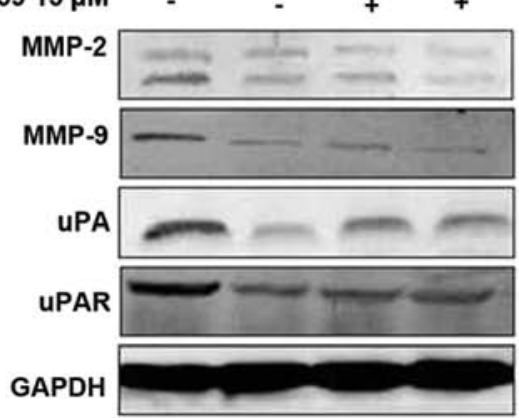

Emodin $80 \mu \mathrm{M}+\mathrm{PD} 9805925 \mu \mathrm{M}$

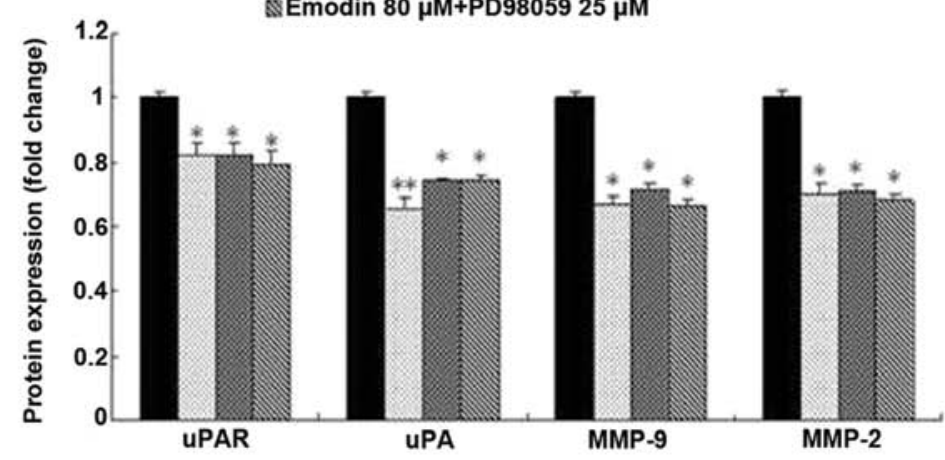

Figure 7. Effect of emodin, PD98059 and their combination on MDA-MB-231 cell invasion and MMP-2, MMP-9, uPA and uPAR expression. (A) A Transwell chamber was used for the invasion assay (magnification, $\mathrm{x} 100$ ). The filter membranes were coated with Matrigel. Cells were untreated (b) or treated with $80 \mu \mathrm{M}$ emodin (c), $25 \mu \mathrm{M}$ PD98059 (d) or $80 \mu \mathrm{M}$ emodin plus $25 \mu \mathrm{M}$ PD98059 (e) for $24 \mathrm{~h}$. (a) Blank (cells were not added). (B) MDA-MB-231 cells were treated with or without $80 \mu \mathrm{M}$ emodin, $25 \mu \mathrm{M}$ PD98059 and $80 \mu \mathrm{M}$ emodin plus $25 \mu \mathrm{M}$ PD98059 for $24 \mathrm{~h}$. The proteins were analyzed by western blotting. The density ratio of proteins to GAPDH is shown as relative expression. Values are expressed as means $\pm \mathrm{SD}$. Experiments were repeated three times. ${ }^{*} \mathrm{P}<0.05,{ }^{* *} \mathrm{P}<0.01$, ${ }_{* * * *} \mathrm{P}<0.001$ vs. untreated cells.
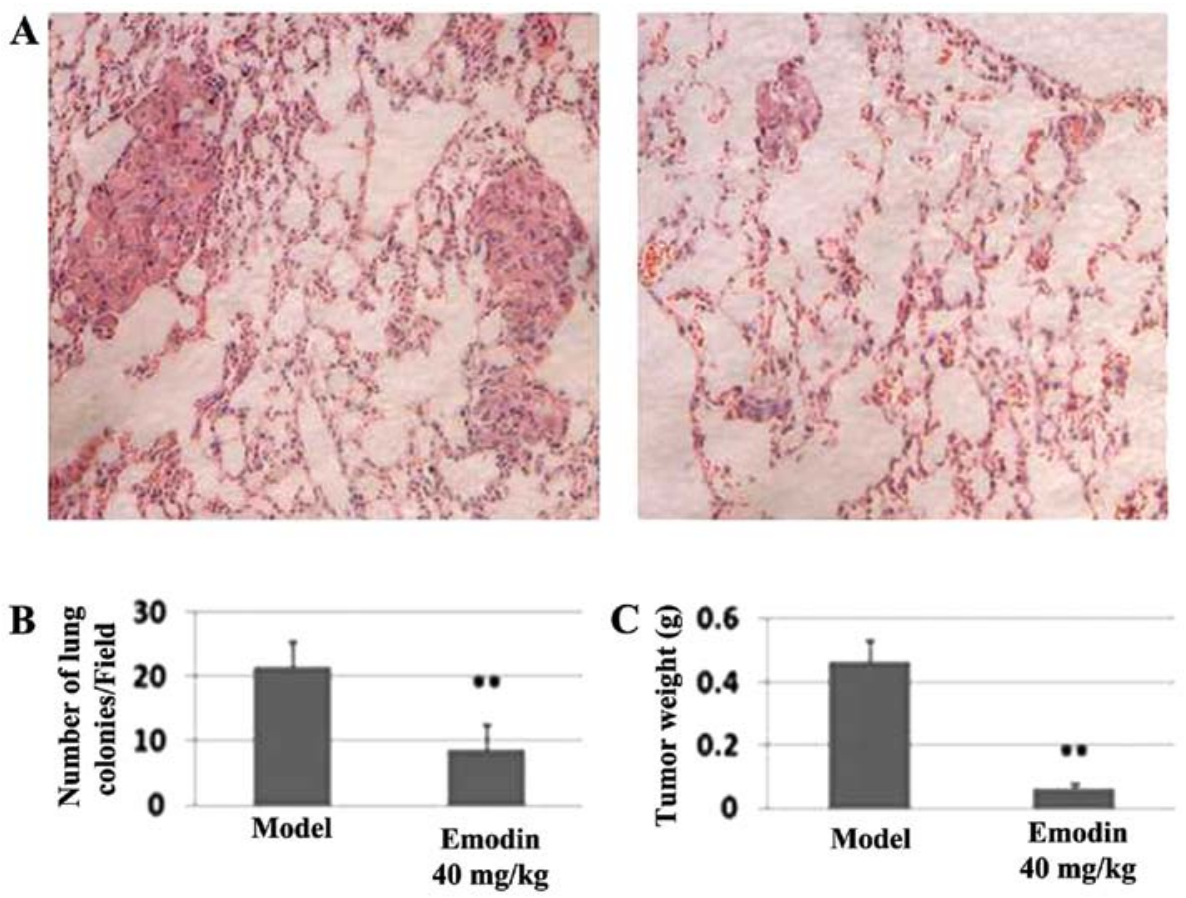

Figure 8. Emodin inhibits tumor growth and pulmonary metastasis in mice bearing breast cancer MDA-MB-231 cell xenografts. Mice received $40 \mathrm{mg} / \mathrm{kg}$ emodin (i.p.) for 8 weeks (n=8). Lung tissues were removed and fixed with Bouin's solution for $24 \mathrm{~h}$. The number of metastatic nodules in the lungs was counted under a dissecting microscope (magnification, x100). (A) Histological appearance of representative lungs from sham- and emodin-treated mice. (B) The quantification of metastatic lung nodules. (C) Tumor weight in the sham- and emodin-treated mice. ${ }^{* *} \mathrm{P}<0.01$ vs. sham-treated group. 

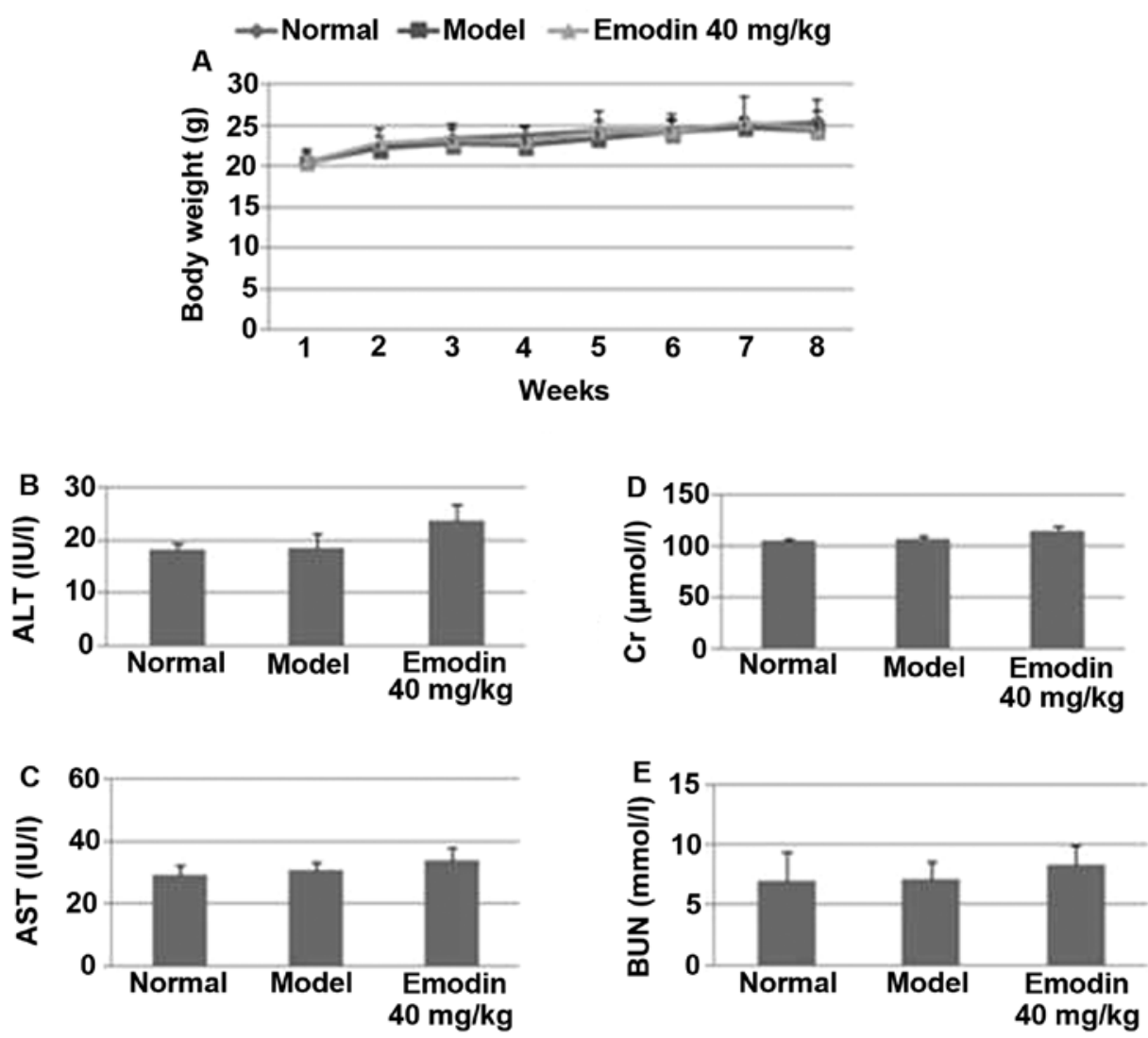

Figure 9. Emodin does not exhibit significant toxicity to the recipient mice. (A) Mice receiving sham or $40 \mathrm{mg} / \mathrm{kg}$ of emodin were weighed weekly for 8 weeks. Data are expressed as means $\pm S D(n=10)$. (B-E) Blood samples were extracted from mice receiving sham or emodin treatment for 8 weeks and were assayed for (B) ALT, (C) AST, (D) Cr and (E) BUN using the respective colorimeter testing kits. Data are expressed as means \pm SD $(n=8)$.

intraperitoneal injection of $40 \mathrm{mg} / \mathrm{kg}$ emodin and vehicle (sham-treated) for 2 months, the metastatic nodules in lungs were evaluated by H\&E-stained sections. The average number of tumor nodules in the sham-treated group was $21.60 \pm 3.92$ while this number was $8.6 \pm 1.51$ in the emodin-treated group $(\mathrm{P}<0.01$; Fig. 8B), suggesting that emodin effectively decreases tumor cell colonization to the lung. Another noticeable difference between the two groups was that the sizes of these nodules were significantly larger in the sham-treated group than those in the emodin-treated group (Fig. 8A). Moreover, the average tumor weight was $0.46 \pm 0.07 \mathrm{~g}$ in the sham-treated group while the average tumor weight was $0.10 \pm 0.05 \mathrm{~g}$ in the emodin-treated group (Fig. 8C), representing over $78 \%$ of inhibition in tumor outgrowth. Together, these results suggest that emodin can block breast tumor outgrowth and metastasis.

Emodin treatment does not elicit side-effects in mice. To determine whether emodin treatment caused side-effects, the body weights of mice were measured every week. Among the normal, sham-treated and emodin-treated groups, there were no significant differences in their body weights ( $\mathrm{P}>0.05$; Fig. 9A). When liver and kidney functions were further analyzed, we found that there was no significant difference in the levels of serum GPT (Fig. 9B), GOT (Fig. 9C), Cr (Fig. 9D) and BUN (Fig. 9E) among the normal, sham- and emodin-treated groups $(\mathrm{P}>0.05)$. Together, these results indicate that emodin can be safely used in vivo for suppressing breast tumorigenicity and metastasis.

\section{Discussion}

Throughout medical history, natural plant products have proven to be valuable sources of novel anticancer drugs, including vincristine, camptothecin, taxel and their derivatives $(27,28)$. Although these natural products have been shown to be highly effective in clinical trials (29), some drugs such as vinblastine and paclitaxel can produce drug resistance (30), and other drugs such as vincristine, produce a strong cytotoxic effect (31). It has also been reported that treatment with topotecan, a water-soluble derivative of camptothecin, caused immunologic suppression in breast cancer (LM2-4) xenografts (32). Therefore, the identification of safer and more effective drugs from natural medical plants for breast cancer metastasis is crucial.

Emodin is a laxative ingredient derived from plants such as Rheum, Polygonum, Buckthorn and Senna (33). Because of its low toxicity, it can be used for medical treatment, as well as for health care and daily supplements such as it is used in hair care and skin care products. It can also be added to natural pigment and laxatives (34). Previous studies have shown that emodin not only has anticancer activity in breast cancer $(9,10)$, but also did not exhibit drug resistance and other side-effects (33). A previous study (13) reported that $40 \mathrm{mg} /$ $\mathrm{kg}$ dosage of emodin suppresses cancer cell growth in vivo, and we found that emodin at this dosage inhibited both tumor outgrowth and spontaneous lung metastasis of breast cancer (Fig. 8), without an obvious change in body weight, liver and 
kidney functions in the mouse MDA-MB-231 cell xenograft model (Fig. 9). Moreover, emodin effectively reduced the invasion and the migration of breast cancer cells (Figs. 2 and 3). These findings indicate that emodin may be a potential safe and effective agent to suppress breast cancer metastasis.

Invasion and migration of cancer cells is an important step in cancer metastasis (35). In advanced breast cancer with poor prognosis, proteolytic enzymes such as MMP-2, MMP-9 and uPA are overexpressed (36), and they play a very important role in ECM and BM degradation (37). Moreover, ECM degradation promotes cell invasion and migration $(38,39)$. Previous studies have confirmed that certain natural products can inhibit cancer metastasis by inhibition of ECM degradation through inhibition of proteolytic enzymes (40). In the present study, we found that emodin not only reduced the invasion and the migration of breast cancer cells, but also significantly inhibited the expression of MMP-2, MMP-9, uPA and UPAR, and the secretion of MMP-2 and MMP-9, even though TIMP-1 and TIMP-2 were not obviously changed in the breast cancer cells (Figs. 4 and 5), which indicated that emodin inhibited the invasion and the migration of breast cancer cells through downregulation of the expression of MMP-2, MMP-9 and uPA, and reduction in the secretion of MMP-2 and MMP-9.

MAPK is an important signaling pathway, which is critically involved in the process of cancer progression and metastasis by regulating cell proliferation, differentiation and apoptosis, angiogenesis, invasion and tumor metastasis $(41,42)$. Both ERK and p38 are important members of the MAPK pathways for cancer invasion and metastasis, which are involved in the regulation of MMP-2, MMP-9 and UPA in breast cancer (43). Previous research has found that certain natural products can inhibit breast cancer metastasis by downregulated the expressions of MMP-2, MMP-9 and uPA through inhibition of the p38 signaling pathway (44). In the present study, emodin as well as SB203580, a p38-specific inhibitor and PD98059, an ERK specific inhibitor, decreased the activation of $\mathrm{p} 38$ and ERK1/2 and the expression levels of MMP-2, MMP-9 and uPA, but the combination treatment of emodin and SB203580 or PD98059 did not obviously alter these inhibitory effects in MDA-MB-231 cells (Figs. 6 and 7). Together, these findings indicate that emodin inhibits breast cancer cell invasion through the downregulation of MMP-2, MMP-9, uPA and uPAR expression and as an inhibitor of $\mathrm{p} 38$ and ERK.

Many reports suggest that, emodin, as an inhibitor, can inhibit a variety of protein kinases such as MAPK and NF- $\mathrm{KB}$ and proteolytic enzymes such as MMPs and uPA, but also inhibits cancer cell invasion and metastasis (45). There is previous evidence that emodin inactivated ERK1/2 in lung cancer H1703 or A549 cells and reduced the phosphorylation of the p38 MAPK in atherosclerosis (46). In breast cancer, emodin suppressed HER-2/neu tyrosine kinase activity in MDA-MB-435 cells, which overexpressed HER-2/neu and thereby suppressing the proliferation of these cells (47). In the present study, we found that emodin inhibited migration and invasion of MDA-MB-231 cells, and also inhibited the expression levels of p-p38 and p-ERK1/2, MMP-2, MMP-9 and uPA. Collectively, the present study suggests that emodin is a non-specific protein kinase inhibitor affecting p38, ERK and proteolytic enzymes, MMPs and uPA in inhibiting invasion of breast cells.
In conclusion, emodin inhibited lung metastasis in mice bearing human breast cancer MDA-MB-231 xenografts in a nude mouse xenograft model. Emodin also inhibited the invasion and migration of MDA-MB-231 cells by downregulating the expression of MMP-2, MMP-9, uPA, uPAR, p-p38 and p-ERK $1 / 2$ and decreasing the activity of p38 and ERK. Furthermore, emodin inhibited the invasion of MDA-MB-231 cells by downregulating the expression of MMP-2, MMP-9, uPA and UPAR as well as decreasing the activity of p38 and ERK.

\section{Acknowledgements}

The present study was supported by the Key Program of the National Natural Science Funds of China (no. 81330084), the Program for Professor of Special Appointment (Eastern Scholar) at Shanghai Institutions of Higher Learning (no. 2012-89) and the E-Institutes of Shanghai Municipal Education Commission (no. E03008).

\section{References}

1. Parkin DM and Fernandez LM: Use of statistics to assess the global burden of breast cancer. Breast J 12: S70-S80, 2006.

2. Wang S, Liu Q, Zhang Y, et al: Suppression of growth, migration and invasion of highly-metastatic human breast cancer cells by berbamine and its molecular mechanisms of action. Mol Cancer 8: $81,2009$.

3. Zhai XF, Chen Z, Li B, et al: Traditional herbal medicine in preventing recurrence after resection of small hepatocellular carcinoma: a multicenter randomized controlled trial. J Integr Med 11: 90-100, 2014.

4. Jin X, Ruiz Beguerie J, Sze DM and Chan GC: Ganoderma lucidum (Reishi mushroom) for cancer treatment. Cochrane Database Syst Rev 6: CD007731, 2012.

5. Lin SZ, Wei WT, Chen H, et al: Antitumor activity of emodin against pancreatic cancer depends on its dual role: promotion of apoptosis and suppression of angiogenesis. PLoS One 7: e42146, 2012.

6. Liu A, Sha L, Shen Y, Huang L, Tang X and Lin S: Experimental study on anti-metastasis effect of emodin on human pancreatic cancer. Zhongguo Zhong Yao Za Zhi 36: 3167-3171, 2011 (In Chinese).

7. He L, Bi JJ, Guo Q, Yu Y and Ye XF: Effects of emodin extracted from Chinese herbs on proliferation of non-small cell lung cancer and underlying mechanisms. Asian Pac J Cancer Prev 13: 1505-1510, 2012.

8. Ko JC, Su YJ, Lin ST, Jhan JY, Ciou SC,Cheng CM and Lin YW: Suppression of ERCC1 and Rad51 expression through ERK1/2 inactivation is essential in emodin-mediated cytotoxicity in human non-small cell lung cancer cells. Biochem Pharmacol 79: 655-664, 2010.

9. Guo J, Li W, Shi H, et al: Synergistic effects of curcumin with emodin against the proliferation and invasion of breast cancer cells through upregulation of miR-34a. Mol Cell Biochem 382: 103-111, 2013.

10. Huang Z, Chen G and Shi P: Effects of emodin on the gene expression profiling of human breast carcinoma cells. Cancer Detect Prev 32: 286-291, 2009.

11. Yu JQ, Bao W and Lei JC: Emodin regulates apoptotic pathway in human liver cancer cells. Phytother Res 27: 251-257, 2013.

12. Yu CX, Zhang XQ, Kang LD, et al: Emodin induces apoptosis in human prostate cancer cell LNCaP. Asian J Androl 10: 625-634, 2008.

13. Cha TL, Qiu L, Chen CT, Wen Y and Hung MC: Emodin downregulates androgen receptor and inhibits prostate cancer cell growth. Cancer Res 65: 2287-2295, 2005.

14. Xue H, Chen Y, Cai X, Zhao L, He A, Guo K and Zheng X: The combined effect of survivin-targeted shRNA and emodin on the proliferation and invasion of ovarian cancer cells. Anticancer Drugs 24: 937-944, 2013. 
15. Yaoxian W, Hui Y, Yunyan Z, Yangqin L, Xin G and Xiaoke W: Emodin induces apoptosis of human cervical cancer hela cells via intrinsic mitochondrial and extrinsic death receptor pathway. Cancer Cell Int 13: 71, 2013.

16. Ma YS, Weng SW, Lin MW, et al: Antitumor effects of emodin on LS1034 human colon cancer cells in vitro and in vivo: roles of apoptotic cell death and LS1034 tumor xenografts model. Food Chem Toxicol 50: 1271-1278, 2012.

17. Wang W, Sun Y, Li X, Li H, Chen Y, Tian Y, Yi J and Wang J: Emodin potentiates the anticancer effect of cisplatin on gallbladder cancer cells through the generation of reactive oxygen species and the inhibition of survivin expression. Oncol Rep 26: $1143-1148,2011$.

18. Chen YY, Chiang SY, Lin JG, et al: Emodin, aloe-emodin and rhein inhibit migration and invasion in human tongue cancer SCC-4 cells through the inhibition of gene expression of matrix metalloproteinase-9. Int J Oncol 36: 1113-1120, 2010.

19. Lin SY, Lai WW, Ho CC, et al: Emodin induces apoptosis of human tongue squamous cancer SCC-4 cells through reactive oxygen species and mitochondria-dependent pathways. Anticancer Res 29: 327-335, 2009.

20. Li WY, Chan RY, Yu PH and Chan SW: Emodin induces cytotoxic effect in human breast carcinoma MCF-7 cell through modulating the expression of apoptosis-related genes. Pharm Biol 51: 1175-1181, 2013.

21. Yan Y, Su X, Liang Y, et al: Emodin azide methyl anthraquinone derivative triggers mitochondrial-dependent cell apoptosis involving in caspase-8-mediated Bid cleavage. Mol Cancer Ther 7: 1688-1697, 2008.

22. Bogenrieder T and Herlyn M: Axis of evil: molecular mechanisms of cancer metastasis. Oncogene 22: 6524-6536, 2003.

23. Eves P, Katerinaki E, Simpson C, et al: Melanoma invasion in reconstructed human skin is influenced by skin cells - investigation of the role of proteolytic enzymes. Clin Exp Metastasis 20: 685-700, 2003.

24. Ahmad A, Wang Z, Kong D, et al: FoxM1 down-regulation leads to inhibition of proliferation, migration and invasion of breas cancer cells through the modulation of extra-cellular matrix degrading factors. Breast Cancer Res Treat 122: 337-346, 2010.

25. Chun $\mathrm{J}$ and Kim YS: Platycodin D inhibits migration, invasion, and growth of MDA-MB-231 human breast cancer cells via suppression of EGFR-mediated Akt and MAPK pathways. Chem Biol Interact 205: 212-221, 2013.

26. Wang XF, Zhou QM, Du J, Zhang H, Lu YY and Su SB: Baicalin suppresses migration, invasion and metastasis of breast cancer via p38 signaling pathway. Anticancer Agents Med Chem 13: 923-931, 2013.

27. Ghosh S, Bishayee $\mathrm{K}$ and Khuda-Bukhsh AR: Oleanolic acid isolated from ethanolic extract of Phytolacca decandra induces apoptosis in A375 skin melanoma cells: drug-DNA interaction and signaling cascade. J Integr Med 12: 102-114, 2014.

28. Cragg GM and Newman DJ: Plants as a source of anti-cancer agents. J Ethnopharmacol 100: 72-79, 2005.

29. Mans DR, Rocha AB and Schwartsmann G: Anti-cancer drug discovery and development in Brazil: targeted plant collection as a rational strategy to acquire candidate anti-cancer compounds. Oncologist 5: 185-198, 2000.

30. Yamagishi T, Sahni S, Sharp DM, Arvind A, Jansson PJ and Richardson DR: P-glycoprotein mediates drug resistance via a novel mechanism involving lysosomal sequestration. J Biol Chem 288: 31761-31771, 2013.
31. Stanley A and Akbarsha MA: Ultrastructural changes in the Leydig cell on treatment with vincristine. Cytobios 79: 51-58, 1994.

32. Francia G, Shaked Y, Hashimoto K, et al: Low-dose metronomic oral dosing of a prodrug of gemcitabine (LY2334737) causes antitumor effects in the absence of inhibition of systemic vasculogenesis. Mol Cancer Ther 1: 680-689, 2012.

33. Srinivas G, Babykutty S, Sathiadevan PP and Srinivas P: Molecular mechanism of emodin action: transition from laxative ingredient to an antitumor agent. Med Res Rev 27: 591-608, 2007.

34. NTP Toxicology and Carcinogenesis Studies of EMODIN (CAS NO. 518-82-1) Feed Studies in F344/N Rats and B6C3F1 Mice. National Toxicology Program. Natl Toxicol Program Tech Rep Ser 493: 271-278, 2001.

35. Price JT and Thompson EW: Mechanisms of tumor invasion and metastasis: emerging targets for therapy. Expert Opin Ther Targets 6: 217-233, 2002.

36. Huang XX, Xu DP, Wang LQ and Gao LY: Expression of MMP-2 and MMP-9 in the tissues of breast carcinoma and its relationship with tumor invasion and metastasis. Chin J Clin Rehabil 8: 2190-2192, 2004.

37. Stamenkovic I: Extracellular matrix remodeling: the role of matrix metalloproteinases. J Pathol 200: 448-464, 2003.

38. Dung TD, Feng CC, Kuo WW, et al: Suppression of plasminogen activators and the MMP-2/-9 pathway by a Zanthoxylum avicennae extract to inhibit the HA22T human hepatocellular carcinoma cell migration and invasion effects in vitro and in vivo via phosphatase $2 \mathrm{~A}$ activation. Biosci Biotechnol Biochem 77: 1814-1821, 2013.

39. Yadav L, Puri N, Rastogi V, Satpute P, Ahmad R and Kaur G: Matrix metalloproteinases and cancer - roles in threat and therapy. Asian Pac J Cancer Prev 15: 1085-1091, 2014.

40. Wang XF, Du J, Zang TL, et al: Chinese herbal formula PC-SPESII inhibits breast cancer metastasis in vivo and in vitro. Evid Based Complement Alternat Med 2013: 894386, 2013.

41. Yao Q, Luo JR, Chen JH, Zhang JL, Yuan SF, Ling R and Wang L: Expression and activation of MAPK pathway signaling molecules in human breast cancer cell lines. Xi Bao Yu Fen Zi Mian Yi Xue Za Zhi 20: 328-330, 2004 (In Chinese).

42. Han YC, Zeng XX, Wang R, Zhao Y, Li BL and Song M: Correlation of $\mathrm{p} 38$ mitogen-activated protein kinase signal transduction pathway to uPA expression in breast cancer. Ai Zheng 26: 48-53, 2007 (In Chinese).

43. Roux PP and Blenis J: ERK and p38 MAPK-activated protein kinases: a family of protein kinases with diverse biological functions. Microbiol Mol Biol Rev 68: 320-344, 2004.

44. Du J, Wang XF, Zhou QM, et al: Evodiamine induces apoptosis and inhibits metastasis in MDA-MB-231 human breast cancer cells in vitro and in vivo. Oncol Rep 30: 685-694, 2013.

45. Tan W, Lu J, Huang M, Li Y, et al: Anti-cancer natural products isolated from Chinese medicinal herbs. Chin Med 6: 27, 2011.

46. Ueno N, Kiyokawa N and Hung M: Growth suppression of low HER-2/neu-expressing breast cancer cell line MDA-MB-435 by tyrosine kinase inhibitor emodin. Oncol Rep 3: 509-511, 1996.

47. Shrimali D, Shanmugam MK, Kumar AP, et al: Targeted abrogation of diverse signal transduction cascades by emodin for the treatment of inflammatory disorders and cancer. Cancer Lett 341: 139-149, 2013. 